\title{
Paclitaxel Injection Concentrate for Nanodispersion
}

National Cancer Institute

\section{Source}

National Cancer Institute. Paclitaxel Injection Concentrate for Nanodispersion. NCI

Thesaurus. Code C96037.

A nanoparticle-based injectable concentrate containing the water-insoluble taxane paclitaxel, with potential antineoplastic activity. Upon reconstitution and administration, paclitaxel binds to tubulin and inhibits the disassembly of microtubules, thereby resulting in the inhibition of cell division. Compared to paclitaxel alone, the nanodispersion-based formulation uses less toxic solvents and allows for administration of higher doses resulting in higher concentrations of paclitaxel at the tumor site, and an increased safety profile. 